\title{
Competência Legislativa em Matéria de Funcionário
}

\author{
HOMERO FREIRE \\ (Procurador da Prefeitura do Recife)
}

I - Lei estadual criou uma situação jurídica a favor dos funcionários. Não aludiu, restritivamente, aos funcionários estaduais.

Teria ela aplicação em proveito dos servidores municipais?

II - Fala-se, freqüentemente, em autonomia comunal como impeditiva da subsunção a fatos de interêsse municipal, de leis do Estado-membro. Os municípios seriam autônomos, e, portanto, o poder legislativo estadual não teria incidência sôbre sua organização político-administrativa.

E tempo de ver até onde chega essa decantada autonomia.

III - Tudo não passa de reminiscência histórica. A célula mater, que era realidade no passado, hoje é figura de retórica, repetida em razão de simples rotina mental.

Cabe repetir a indagação do mestre Pontes de Miranda: o que nos resta dos municípios romanos e das comunas medievais?

Esses sim, formavam um organismo vivo, atuante, foram o cerne da nacionalidade.

Na época atual, diz o emérito constitucionalista, os municípios não são mais do que uma "porção de espaço", talvez sem unidade real, sem mesmo a geográfica, em que se divide, para comidade administrativa, e, não raro arbitràriamente, o território dos Estados do Século XX (PONTES DE MIRANDA - "Comentários à Constituição de 1946", vol. I, pág. 478).

IV - No Brasil o panorama é expressivo, sem embargo do plurido municipalista que, parece, já não coça tanto.

Pedro CAlmon atesta: a República manteve o município, mas subordinado inteiramente aos Estados que o organizariam como entendessem ("Curso de Direito Constitucional Brasileiro", pág. 100).

Enquanto o Estado participa da formação da vontade nacional, os municípios são apenas divisão administrativa do mesmo Estado (PEDRO CALMON - obra cit., pág. 66).

V - Realmente, o que ressalta na atualidade é a personalidade nacional, é o poder federal, discriminando, através dos órgãos representativos da vontade coletiva, a esfera de competência segundo a conveniência e os interêsses gerais. 
A favor do Município dá-se a competência mínima, na fórmula constitucional "da administração própria no que concerne ao seu peculiar interêsse" (inciso II do art. 28 da Constituição Federal).

Pontes de Miranda explica: "O povo de cada Província e o povo de todo o Estado é que podem julgar da oportunidade e da conveniência de normas sôbre as Comunas. O povo da Província, porque conhece as circunstâncias geográficas, econômicas, políticas, do território provincial, e o povo do Estado, porque o conjunto das experiências e convicções, quanto à vida nacional, nas suas relações com os Municípios, the sugerirá o melhor modo de resolver o problema da descentralização." (obra e vol. cits., pág. 481).

A União, que personifica jurìdicamente a Nação, dispõe originàriamente, da competência total, abrangedora de todos os problemas estatais, para exercêla por si; mas, constitucionalmente, devolve-as parcialmente às entidades inferiores. Recebendo da União parte daquela competência, os Estados-membros, por sua vez, a transferem, em parte, às Comunas, e, daí, a gradação das competências.

VI - Em que limite se situa a competência mínima, jure delegato, do Município? - Na "autonomia" discriminada no art. 28 da Constituição:

a) eleição dos órgãos dirigentes;

b) administração dos serviços internos;

c) organização dos serviços públicos locais.

Volvendo à lição de Pontes DE MiRAnda: "O que se deve evitar é o monopólio da administração pública por parte do govêrno estadual, ou dos govêrnos provinciais; por sugestão das próprias coisas administrativas e no interêsse de aplicação de certos impostos nos lugares em que foram percebidos, de certas verabs recebidas de pessoas de uma "porção espacial" a pessoas e interêsses que são do mesmo círculo."

E mais de espaço: "Nos nossos dias, autonomia municipal é, apenas, caso particular de técnica organizatória do Estado" (obra e vol. cits., pág. 482),

Quem cria e quem modela política e administrativamente o Município, é a Lei Maior, ou, devolutivamente, a lei do Estado-membro, a lei orgânica votada pelo poder legislativo estadual. Só depois de criado e insuflado de personalidade, é que o Município passa a ter vida autônoma.

Veja-se a lei estadual 445 , de 4 de janeiro de 1949 , de organização municipal do Estado de Pernambuco: estabelece os requisitos necessários e suficientes à constituição de um Município: extensão de área; limite de população; número de casas de alvenaria; renda mínima; corpo eleitoral em determinado número, etc. (art. $4 .^{\circ}$ e seus incisos).

Esses dados são apurados pela Assembléia Legislativa, a quem cabe a elaboração da lei de criação dos Municipios (art. $5 .^{\circ}$ ).

O Município não existe por sí; nasce, jurìdicamente, de lei do Estado, e se desvincula do ventre materno para uma vida autônoma dentro das raias constitucionais. 
Quer dizer, vida autônoma no sentido de o próprio município eleger seus órgãos dirigentes, de êle mesmo decretar e arrecadar seus tributos, aplicando-os segundo suas próprias resoluções, de êle mesmo prover e regular os serviços locais, tais como fechamento do comércio, localização do meretrício, concessão de serviço de luz, fôrça e telefones, etc. (Ver Francisco Campos - "Direito Administrativo, pág. 168-169.

Não vai muito além.

VII - Há problemas, no entanto, que, embora interessem diretamente às Comunas, ou pareçam interessar-lhes exclusivamente, transcendem o círculo da autonomia municipal. São problemas politicamente comuns aos Municipios, aos Estados e à própria União, e, daí, o extravasamento dos confins municipalistas para o oceano largo do ordenamento jurídico de grau superior.

interêsse geral ou público que os envolve, junge-os aos que lhes são semelhantes no campo federal ou estadual, e, por isso, uns e outros devem subordinar-se às mesmas normas fundamentais.

As disposições dessa ordem merecem qualificação programática no direito constitucional, subordinando ao seu mandamento tôdas as entidades de direito público que compõem o govêrno do país.

Exemplo: o status do funcionário público, matéria que, no sistema do nosso Direito, deixou de ser de natureza simplesmente administrativa para alçar-se às honras da regulação constitucional (Título VIII da Constituição Federal).

Como diz Temístocles Cavalcanti, alguns direitos, os mais essenciais, dos funcionários públicos, têm sido consagrados nos textos constitucionais e gozam, por isso mesmo, de um caráter de imutabilidade e generalidade inerentes às disposições constitucionais (grifo nosso) (TEmístocles CAVALCANTI - "Tratado de Direito Administrativo", vol. III, pág. 55).

Visou, o legislador constituinte, assegurar um mínimo de garantias, ampliàvel pelas entidades menores, mas não restringível (Ver acórdão do Supremo Tribunal Federal, de 14 de junho de 1950, publicado no "Diário da Justiça" de 28 de março de 1952, pág. 1598, do apenso).

Consulte-se o prof. FRANCISCO DE CAMPOS, bem escorado em comentadores alemães dá Constituição de Weimar: "O que a Constituição teve em vista foi criar aos funcionários uma situação independente e garantida, a qual favorecesse a formação de uma carreira do serviço, com os atributos de competência e de estabilidade, garantias de decência e a segurança de amparo, em caso de invalidez, de maneira a colocá-los a salvo das vicissitudes da política, bem como dos cuidados e apreensões com a própria subsistência."

"Tais garantias e segurança - é ainda o Prof. CAMPos quem fala - a Constituição não restringiu aos funcionários federais, mas tornou extensivas, de mocio geral ou indistintamente, a todos os funcionários, sem discriminá-los pela natureza de sua investidura ou pela esfera federal, estadual ou municipal da sua competência. A todos os funcionários, pois, se aplica o título VIII da Constituição, e, portanto, assim aos dos Estados, como aos dos Municípios." ("Direito Administrativo", págs. 105-106). 
VIII - As regras da Constituição Federal sôbre o funcionalismo, abarcam, pois, não só o plano federal, como o estadual e municipal, e sôbre isso ninguém discrepa.

A nossa Constituição do Estado, por sua vez, em círculo menor, aponta o mesmo fenômeno quando manda que lei especial organize o Estatuto dos Funcionários Públicos do Estado e dos Municípios, na conformidade dos princípios do Título VIII da Constituição Federal, e das normas que prefixa e enumera no art. 163 .

O propósito foi colocar todos os servidores públicos do território do Estado, no mesmo pé de igualdade quanto aos direitos fundamentais da função pública: férias em período uniforme, reconhecimento, para determinados efeitos, do tempo de serviço às outras entidades de direito público, gratificação por tempo de serviço, licença-prêmio, direito a recurso contra decisão disciplinar, e de revisão de processos administrativos, extensão da estabilidade aos servidores extranumerários, extensão do abono familiar aos aposentados, preferência no preenchimento dos cargos de início de carreira a favor dos extranumerários, repouso semanal remunerado, etc. (incisos do art. 163 da Constituição do Estado de Pernambuco). Procurou-se evitar disparidade de tratamento e desrespeito aos direitos considerados essenciais aos funcionários públicos, eis que a tanto conduziria a liberdade de regulação da matéria, da parte das legislaturas municipais.

Essa preocupação igualitária não se cingiu e nem poderia cingir-se aos preceitos referidos na Constituição do Estado. Por fôrça mesmo dos objetivos morais, políticos e jurídicos que perseguem tinham de revestir-se de uma permanência irrecusável.

A todo o momento em que a lei estadual adiciona novos direitos subjetivos em prol do funcionalismo, sem distinguir, sem restringir, sem excluir, por via de conseqüência aplica-se genèricamente a todos os servidores públicos do território do Estado, inclusive, portanto, aos dos Municípios que o compõem. Só dêste modo será possível assegurar e conservar a igualdade de tratamento no que diz respeito ao minimum que o legislador estadual considerou necessário estatuir.

IX - Há, pois, em assunto de funcionário, na sistemática do -lireito público brasileiro, competência legislativa concorrente, federal, estadual e municipal, em círculos concêntricos, obrigados os Estados-membros, dentro do âmbito estadual, a seçuir o esquema da Constituição Federal, e os Municípios, no âmbito municipal, a respeitar os esquemas da mesma Constituição e o da Constituição estadual, quanto ao mínimo dos direitos estabelecidos.

$\mathrm{X}$ - Isto no plano do direito constitucional.

Mas, cabe averiçuar se a concorrência da atuação legisferante sôbre a matéria, da União e dos Estados-membros em relação aos Municípios, se extende ao campo da lei ordinária.

$\mathrm{O}$ índice de autonomia política (self-ogvernment) dos Estados-membros oferece a diferenciação.

No regime brasileiro, os Estados participam da formação da vontade nacional, disse PEDRo CALMON (obra cit., pág. 66). Gozam do direito de auto- 
organização político-administrativa, subordinados apenas aos dados primários estabelecidos na Constituição Federal (art. 18): decretam suas próprias Constituições e suas leis, e exercem todos os poderes estatais que desdobram dos limites de poder reservado constitucionalmente à União ( $\S 10^{\circ}$ do art. 18).

Essa amplitude de dominação política local que, com maior ou menor intensidade ou quantidade, caracteriza a organização do Estado federado, explica o trancamento da competência legislativa ordinária federal, em matéria de funcionário, além de outras mais, em frente à competência da mesma ordem, estadual, bem entendido no que tange ao funcionalismo estadual e municipal.

E, de outro lado, considerada a inferioridade jurídica dos Municípios, tão sòmente administrativamente autônomos, simples "porção espacial" do Estado-membro, ressai a aplicação da lei ordinária estadual também sôbre o complexo de direitos dos funcionários municipais.

Em síntese: a Constituição Federal dá o mínimo geral; a Constituição local pode elevar o mínimo geral-estadual. A lei ordinária federal, dando mais, dá apenas aos funcionários federais; a estadual, dando mais, dá a todos os funcionários do território do Estado, salvo exclusão expressa ou referência exclusiva aos seus funcionários; o Município, dando mais, dá apenas aos funcionários municipais.

Razão por que tenho por aplicável no plano municipal, a situação jurídica criada pela lei estadual em exame, que dispõe genèricamente a favor dos funcionários, sem restrições.

Os princípios de justiça social, que informam a política de trabalho do Estado para com seus empregados, não podem ter aplicação prática na ausência de um Plano de Classificação, baseado nos deveres, atribuições e responsabilidades funcionais dos servidores. O Plano de Classificação é o único instrumento capaz de assegurar a aplicação dos princípios da justiça social às relações entre o Estado e seus funcionários. A adoção de um plano dessa natureza vai permitir, pela primeira vez, no Serviço Público Federal, que o Estado disponha de instrumento adequado de classificação e retribuição ao funcionalismo. As situações anômalas, que tanto desestímulo acarretam, deverão desaparecer mediante o estabelecimento de um sistema através do qual a administração e os servidores encontrem um denominador comum para expressarem seus pontos de vista.

ARízio DE VIANA: D.A.S.P. - Instituição a Serviço do Brasil - 1953). 